PSYCHOMETRIKA-VOL 12, NO. 4

DECEMBER, 1947

\title{
A FACTORIAL STUDY OF FLUENCY IN WRITING*
}

\author{
Calvin W. Taylor \\ THE UNIVERSITY OF CHICAGO
}

\begin{abstract}
A factorial study of fluency was undertaken to test an hypothesis that at least two fluency abilities would be measured by a battery composed both of word fluency tests used by Thurstone and tests of fluency described by several British investigators. Twenty-eight tests, including ten reference tests for five primary mental abilities, were administered to $181 \mathrm{high}$-school seniors. Ten centroid factors were extracted, a simple structure was found, and eight factors were interpreted. Five factors defined were the following reference abilities: memory $(M)$, number $(N)$, reasoning $(R)$, verbal comprehension $(V)$, and perceptual speed $(P)$, the last one being somewhat tentatively identified. The main finding is the analysis of fluency into two factors: word flcency $(W)$ and ideational fluency $(F)$. Word fluency is defined as a facility in producing single, isolated words that contain one or more formal restrictions, without reference to the meaning of the words. Ideational fluency is described as a facility in expressing ideas by the use of words and their meanings. Another verbal ability indicated is tentatively interpreted as verbal versatility, the ability to express essentially the same idea by means of several different words or combinations of words.
\end{abstract}

\section{Introduction}

There have been several studies of fluency in which factor techniques or other experimental methods have been applied. Some of the main investigations have been made by the Thurstones $(17,18,20)$, by Carroll (1), by Johnson and Reynolds (10), and by several contributors to British journals, including Cattell $(3,4)$, Hargreaves (8), Notcutt (13), Stephenson (14), and Studman (15). In these studies numerous tests have been described and defined as measures of fluency.

In Thurstone's first study (17) and particularly in the Thurstones' latest study (20) concerning fluency, a clear separation between verbal comprehension ability $(V)$ and word fiuency ability $(W)$ was indicated. The word fluency factor was described as the ability to produce words in accordance with some restriction, as dis-

* The writer wishes to express his appreciation to Dr. L. L. Thurstone for his guidance throughout the study and for providing facilities and materials needed; to Miss Jessie LaSalle and the Washington, D. C., high schools for providing the subjects; to Ledyard Tucker, Frank Medland, and Mrs. Virginia Brown for computational assistance; and to others who gave aid during the study. 
tinguished from the ability to understand words when they are given in a test. The following types of tests proved to be the best measures of word fluency: Prefixes, First Letters, First and Last Letters, FourLetter Words, and Suffixes.

The concept of fluency as discussed by various British investigators has been very broad, apparently including facility both in speech and in writing and also bearing a close relation to a general temperamental factor which Cattell named Surgency. This relation is considered to be sufficiently high for results in written fluency tests to be interpreted in terms of temperament; in fact, Cattell has stated that, of all the objective tests yet discovered for testing temperament, none are so valid as are the fluency tests for Surgency.

Cattell and Studman seemed to agree quite closely in their description of fluency. Studman also favors the term "Surgency" as the one that best describes the nature of the trait being measured by fluency tests. Other discussions of fluency mention the functioning of critical-mindness, self-criticism, and "inhibitions at lower levels," plus a surging pressure of mental activity which, especially in more fluent persons, counteracts and readily overcomes these hindrances to expression (15).

Hargreaves (8) reported fluency of imagination to be a complex factor consisting of " $g$ " plus memory plus speed plus " $x$," the nature of " $x$ " and of speed being not clear, but probably best to be described in conative terms, namely, as an absence of self-criticism, which might lead to a preference for quantity over quality. More recently Notcutt (13) has claimed to have confirmed the existence of a group fluency factor, but did not find it to correlate with self-ratings of Surgency, at the same time pointing out the inadequacies of these ratings.

The fluency tests used in the British studies include the following types: Words beginning with $S$, Four-Letter Words, Two-Syllable Words, Subsumption (to list things that are round, little, etc.), Topics (to write as much as possible about a vague topic such as "a dog barking," "a parcel," etc.), Adjectives, Form Completion, and Ink Blots. It is evident that the first of these tests are very similar to some of Thurstone's best measures of word fluency.

In 1941 when the present study was planned, Thurstone had isolated and interpreted only two factors which were considered to be essentially verbal in nature, namely, $V$ and $W$. It appeared improbable that the word fluency factor, $W$, was adequate to explain the individual differences found in speaking and in writing. In fact, Thurstone stated, in interpreting $W$, that people who excel in this ability might be expected to be clever with words and facile in speaking and 
writing, but that effective oral and written language might also depend upon other factors.*

Strong evidence that language behavior is too complex to be described by a very small number of factors is found in the wide variety of symptoms, plus the numerous combinations of these symptoms, that have appeared in aphasic patients.

Accordingly, it seemed quite probable that at least two different psychological processes might be involved in a battery including tests of Thurstone's word fluency and tests used in different British studies of fluency. One possible hypothesis was that the ability needed in producing words in sentence form might be different from one required in listing isolated words where one word has no particular bearing on the next one. Another hypothesis was that the ability required in listing words that fall within certain arbitrary constraints may be different from one involved when words are produced according to their meanings.

In testing the above hypotheses it would also be possible to determine what relation existed between Thurstone's word fluency factor and the fluency factor found by means of different factorial methods by British investigators.

It was decided that a factorial study using Thurstone's techniques would provide the best method of testing the hypotheses on fluency. In order to insure that any new factors found would be different from the primary mental abilities isolated in previous investigations, it was decided to include in this study, as reference factors, all of these abilities which might conceivably be pertinent to fluency. Ideas for the experimental tests were mainly taken from the literature, and adaptations were made so that each test would be in a form most suitable for the problem under investigation. All tests in the battery required either a recognition or a written type of response.

Carroll's factorial study of verbal abilities (1) appeared in the literature after the design of the present experiment had become fairly crystalized. His factor $A$ is somewhat similar to the word fluency factor $W$ and is discussed in some detail later. The flow of responses factor found in the verbal study by Johnson and Reynolds (10) is also relevant to the present study and will be mentioned later.

\section{The Tests}

A complete list of the tests in the battery is contained in Table 1. This table also shows the ten tests used to measure reference abilities

* This interpretation was given with primary mental ability scores to subjects who participated in the perceptual investigation by L. L. Thurstone in 19412. 
in this study. All reference tests are the same as or similar to ones used previously by the Thurstones (20) in the eighth-grade study, but the time limits may differ from those set for the eighth-grade sample. In addition, tests 11 to 16 have also been used in the present form or in a similar form in the eighth-grade study and in various other studies by Thurstone.

Before the fluency tests were administered, general instructions were given not to write proper nouns (including proper names), foreign words, or plurals on any of the word-listing tests. The tests used are described briefly below.

First Names (1).-This memory test contained 20 items, each consisting of a first and a last name, such as "Ruth Preston." Each name to be memorized was presented on a flash card. After each card had been exposed for 15 seconds in the front of the room, the subjects were required to check on the answer sheet the correct first name for the last name given.

Word-Number (2).-This memory test also was administered by flash cards. Each card contained a word and a two-digit number, such as "chair-21." After each of the 16 test cards had been exposed for 15 seconds, the subjects were told to turn to their answer sheet and mark the correct number for the word given in each item.

Identical Numbers (3).-This perceptual test consisted of 30 columns of three-digit numbers, each column having a key number and 29 numbers beneath it. The subjects were to mark the numbers in each column that were identical with the key number at the top of the column.

Mirror Reading (4).*-This test consisted of 50 columns of five words. The first word in each column was printed forward and below it were four words printed backward (mirror image). One of the four words printed backward was the same as the first word in the column. The task in each column was to mark the word printed backward that was the same as the first word.

Letter Series (5).-This reasoning test contained 30 items. The subjects were asked to study each series of letters, decide what the next letter should be, and mark the letter in the answer row at the right. One sample series follows:

$$
\text { c ada e af } a-\quad \stackrel{a}{=} \stackrel{d}{=} \stackrel{e}{=} \stackrel{f}{=} \stackrel{g}{=}
$$

- In some investigations the Mirror Reading test has been called "Backward Writing." 
Letter Grouping (6).-There were 30 problems in this reasoning test. A sample practice exercise was as follows:

Three of the groups of letters below are alike in some way. Can you find three groups which are alike? Mark the one that is different.

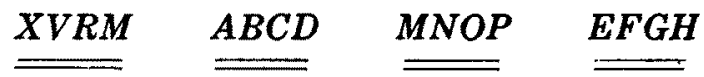

Addition (7).-This number ability test consisted of 56 problems, each one containing a column of six two-digit numbers with a sum at the bottom of the column. The task was to mark whether the sum was right or wrong.

Multiplication (8).-This was a number ability test in which a two-digit number was multiplied by a one-digit number to give a product. The subjects marked whether the product shown was right or wrong.

Same or Opposite (9).-This verbal comprehension test consisted of 100 items. The subjects were asked to select from four choices the word that meant the same as or the opposite of the given word in each item.

Completion (10).-This was a test of verbal comprehension consisting of 41 items. A sample practice problem is given below to indicate the nature of the test.

The following sentence has a ward missing at the place indicated by the parentheses. You are to think of the word that best completes the meaning of the sentence.

A (4) is a contest of speed.

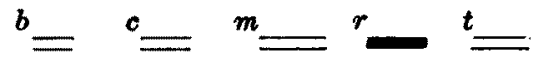

The missing word is race. The number in the parentheses is the number of letters in the missing word. The letter $r$ has been marked because it is the first letter in the missing word.

First and Last Letters (11). - The test instructions were to write as many words as possible which begin with $T$ and $e n d$ with $E$.

Suffixes (12).-In this test the subjects were asked to write as many words as they could which end with tion.

Synonyms (13).-The subjects were told to write three synonyms for each of the 18 words (e.g., dark, expensive, happy, etc.) given in this test.

First Letters (14).-The instructions were to write as many words as possible that begin with $S$. 
Anagrams (15).-In this test the subjects were told to write as many words as they could using the letters in the given word, ABBREVIATION.

Disarranged Sentences (16).-This test consisted of 81 sentences in which the words were jumbled up. If the words were properly rearranged, they formed a statement which was either true or false. The subjects were asked to mark whether each disarranged sentence was true or false. One sample sentence was: "eyes some brown are."

Adjectives (17).- In this test the subjects were asked to write ail the adjectives that they could possibly use to describe $a$ house.

Similes (18).-Fifteen incomplete similes were listed in the test and the subjects were to write three ways (using words or phrases) in which each simile could be completed. A sample exercise was as follows: "His skin was as brown as . . . . ."

Paired Opposites (19).- - The subjects were asked to write pairs of opposites in each double blank on the test. No leads, such as first letters or first words, were presented.

Letter Star (20).-This test contained the 75 items developed and used by Carroll (1). The subjects were told that they would be given a group of letters and stars such as "* $\mathrm{P} * \mathrm{H}$." Each group could represent a sentence, a phrase, a question, or any other meaningful arrangement of words. Each letter or star stands for the first letter of a word. The star can be any letter in the alphabet. An example with one possible answer is shown below.

$$
W * * C-\text { Where is the candy? }
$$

Unfinished Stories (21).-This test was essentially the same as one used by Hargreaves. The subjects were asked to write a clear, meaningful continuation of a story from a given beginning which was as follows: "Once upon a time a boy was so late coming home from school that his parents became very worried. At last he arrived home safely, though very tired, but with his cap and one boot missing. He told them what had happened, which was this: When he left school

Number of Letters (22).-This test was similar both to a FourLetter Worcs test used by the Thurstones and to a Four-Letters subtest used by Studman. The test instructions were to write as many words as possible that have three letters.

Topics (23).-The subjects were required to list many ideas for 
one topic instead of a few ideas for each of several topics as in a Topics test used in British studies. The following directions were given:

Often, as in conversations, it is good to have many ideas about a topic. See how many ideas you can think of about the topic you are to be given. Be sure to list all the ideas you can about the topic whether they seem trivial or nct. You are not limited to one word. Instead you may use a phrase to express each idea.

The topic used was "A man going up a ladder."

Given Letters (24).-The task was to write as many words as possible that conformed with the one restriction, namely, that each word must contain the letters $R$ and $M$. No restriction on the position of these letters or on any other aspect of the words was imposed.

Sentence Fluency (25).-The subjects were to write a variety of different sentences, each one stating essentially the same general idea. The test problem follows:

Suppose that in a certain campaign you were canvassing for a candidate, Mr. Jones. You want to write several of your personal friends and tell them to vote for Mr. Jones. You want to state this thought in a single sentence. Yet you want to write a different sentence to each of your friends. Write as many different sentences as you can that serve this purpose. Limit each sentence to one line.

Things Round (26).-This test was similar to one used by Cattell (5) in which the subjects were asked to list words that were appropriate for each of several successive categories. In the present test the category was "things that are round or that could be called round."

Things to Eat (27). - The subjects were asked to list all the things they could that came within the category, "things to eat."

Theme (28).-The test directions are given below.

In this test you are to write about a given topic. Be sure to write all you can about this topic. Use all the ideas you can think of whether they secm trivial or not. Expand on any idea as much as you like. When you have written all you can about an idea, start a new paragraph and write on another idea about the topic. Just be sure to write as much as you can about this topic.

The topic for the test was "a parcel."

\section{Procedure and Results}

Three groups of high-school seniors from Central, Eastern, and Roosevelt High Schools in Washington, D.C., were tested in this study with the battery just described. Students who did not taike all the tests were eliminated from the sample, leaving a total of 181 cases 
with complete data: 58 students from Central, 52 from Eastern, and 71 from Roosevelt. These 181 seniors, then, formed the sample on which the study was based. The testing was done in November, 1941, a few weeks after the students had started their senior year.

The test battery was administered to each group of students in a two-hour session on each of two successive days. A brief rest period was allowed each day after the first hour of testing.

Intercorrelations between the tests were obtained by means of the Pearson product-moment formula. These correlations are shown in Table 2. The ten factors extracted from the correlation matrix are contained in the centroid martix of Table 3 . The communalities for the tests are listed in the last column of this table.

After nine factors had been obtained, the critical value of a criterion suggested by Coombs (6) for determining the point at which factoring can be terminated had been reached. However, in order to be doubly certain that an adequate number of factors had been obtained, a tenth factor was extracted. The numerical values of the final residuals ranged from .06 to -.07 . The root-mean-square deviation of these residuals from zero was .023 .

A simple structure was found by using both the single plane (19) and the radial methods of rotation. The final solution obtained is presented in the rotated factorial matrix, Table 4. Examination of this table and of the plots of its factors indicates that a clear simple structure was found. On every factor more than half of the entries were zero entries (projections from .10 to - 10 ), the number of zero entries ranging from 16 to 24 for the ten factors. There were no large negative values, the projection of -.13 being the only one that was larger than -.10 .

The transformation from the centroid matrix to the rotated factorial matrix is given by the final transformation matrix in Table 5. The cosines of the angles between the reference vectors are contained in Table 6. The correlations between the ten primary factors in the simple structure are shown in Table 7 . It should be noted that the correlations were generally quite low between the five reference factors and the two new verbal factors, $\mathrm{F}$ and $\mathrm{K}$.

In order to present the simple structure more clearly and to facilitate the process of interpretation, a matrix showing the factorial pattern is given in Table 8 . This pattern matrix was obtained by omitting all entries below .30 from the rotated factorial matrix (Table 4) and then rearranging the order of the rows (the tests). The structure thus presented is quite clear, showing practically no overlap among the first seven factors listed. A check was made to see what 
additional entries would occur in the factorial pattern if the limit were lowered to include entries from .25 to .29 , inclusive. It was found that there would be additional entries only in Factor $P$, which had only one entry above .30, and in Factor $C$, which was not interpreted.

Further inspection of the factorial pattern indicates that, except for the Word-Number test, none of the reference tests (tests 1 to 10) had appreciable loadings on any but the first five factors; and except on Factor $P$, at least two of these reference tests had projections above .30 on each factor. Furthermore, 16 of the 18 experimental tests (tests 11 to 28) did not have loadings on any of the first five factors, but these 16 tests all had an appreciable projection on at least one of the next three factors, $W, F$, or $K$. These three factors were strongly determined structurally in terms of the number of tests with high loadings as well as in terms of the number of tests with zero entries.

\section{Interpretation}

Factor M.-Two tests had projections above .30 on this factor. They were the First Names test (1), with a projection of .59, and the Word-Number test (2), with one of .34. Factor $M$ is interpreted as memory reference ability, that is, rote learning of simple associations with immediate recall. The flash card method of presentation on these tests was different from the usual presentation of items in booklet form. Nevertheless, the memory ability $(M)$ did appear clearly in the simple structure, and no correlations above .23 were found between it and other primary factors in this study.

Factor $P$.-The only test with a high loading on this factor was Identical Numbers (3), with a projection of .49. The other test selected in addition to Identical Numbers as a perceptual reference test was Mirror Reading (4), which had a loading of .28 on this factor. Its main loading appeared on factor $R$. Most other tests with loadings (.28 or .27) on factor $P$ have some perceptual requirements. These tests include Multiplication (8), Anagrams (15), Disarranged Sentences (16), and Synonyms (13). Synonyms is the only one without some obvious perceptual characteristics. Consequently, factor $P$ is tentatively interpreted as a perceptual speed factor, although this identification is not as strongly supported as is desirable.

Factor R.-The three tests that had high projections on this factor were the Mirror Reading test (4), with a projection of .55 ; the Letter Series test (5), with one of .49 ; and Letter Grouping (6), with one of .47. Factor $R$ is interpreted as the reasoning ability reference factor, since the two reference reasoning tests had high loadings on it and no appreciable loadings on any other factor. 
The appearance of Mirror Reading on this factor warrants some explanation. Inspection of this test indicates that it could be quite susceptible to different methods of solution. Some may be a combination of reasoning and perceptual methods while others may be more strictly perceptual in nature. For example, one or more of the wrong choices could be quickly eliminated by finding a simple rule and applying it to the mirror-image words. One such rule is that all mirrored words end with the same letter; only the beginnings of the mirrored words need, therefore, be examined. As one worked further, he might notice that in most cases only the first two mirrored letters need be inspected to determine the correct answer. By means of these rules a great deal of the perceptual task could be eliminated and the remaining perceptual task greatly simplified. Mirror Reading had a higher loading on $\boldsymbol{P}$ in the eighth-grade study, at which level students would probably less likely utilize the above rules in their work method on this test.

Factor N.-Three tests had appreciable loadings on this factor, the Multiplication test (8), with a loading of .71; the Addition test (7), with one of .59 ; and the Word-Number test (2), with one of .30 . Factor $N$ is interpreted as the number facility reference factor. The only other test with a loading above .07 on this factor was also a test employing number symbols, namely, the Identical Numbers test (3), with a projection of .24 .

Fastor $V$. - The following tests had high loadings on this factor.
9. Same or Opposite .74
16. Disarranged Sentences .... .60
10. Completion .74
19. Paired Opposites .43

Factor $V$ is interpreted as the verbal comprehension reference factor. This ability is more one of recognition than of recall; and the meaning of sentences and also the meaning of, and the relation between, pairs of words are its particular field. The same ability is apparently required in the recognition of pairs of words that have the same or the opposite meaning as in the production of pairs of words that have opposite meanings.

Factor $W$.-The following tests had high saturations on this factor.

11. First \& Last Letters ......... .56

12. Suffixes …............................ .50

14. First Letters ...................... .48

24. Given Letters ........................43

22. Number of Letters ............ .38

15. Anagrams .......................... .36

This factor is interpreted as word fluency ability, a facility in producing single, isolated words that contain one or more formal re- 
strictions, without reference to the meaning of the words. Words are selected and produced through a process based upon their structure rather than upon their meaning.

There have been some indications and statements before that meaning requirements are minimized in the word fluency factor.* This study, however, shows clearly that the meaning of words is not involved in any of the six tests that had appreciable loadings on the $W$ factor. There were only six word-listing tests in the battery with purely formal restrictions and all these tests, and only these tests, had appreciable projections on this factor.

A comparison between the First and Last Letters test and the Given Letters test indicates that a word-listing test with two or three well-defined structural restrictions will be a better measure of word fluency than a test with only one formal restriction, permitting a wider variety of work methods. Further support for this conclusion is found in the fact that the Number of Letters test (to write threeletter words) did not have in this study as high a projection on $W$ as did the Four-Letter Word test in the eighth-grade study. In the latter test, not only the number of letters but also the first letter was specified.

In some respects this factor differs from Carroll's factor $A(1)$, which was described as the speed of word association (usually of common words) where there is some element of restriction in the task imposed; i.e., where only one or a certain number of responses from the total word reserve are correct. In interpreting his factor, Carroll made no reference whatsoever to the meaning of the words. There were also some tests with loadings on his factor which had restrictions such that only one response per item was correct. On the other hand, in the present study all the word fluency tests imposed restrictions so broad as to allow a large pool of words (e.g., all words that begin with " $S$ ") to meet the test requirements. On all tests the subjects were given only one general task, which was, in essence, to produce from this pool of appropriate responses as many words as possible within the time allotted. It is thus believed that any test allowing only one correct response per item would not be one of the

* The best example of such statements is found in the interpretation of primary mental ability scores given by $L$. $L$. Thurstone to the individuals who served as subjects in his factorial study of perception in 1941-2. The interpretation began as follows: " $W$-Word Fluency, which is represented in tests requiring the fluent production of words in various contexts independent of the meaning involved." However, some of the strength of this initial statement regarding the role of meaning is lost in his further description, one sentence later, of word fluency. "People who excel in this ability might be expected to be.... facile in speaking and writing. Effective oral and written language may also depend upon other factors." 
better measures of word fluency.

Factor $F$.-The following tests had loadings above .30 on this factor.

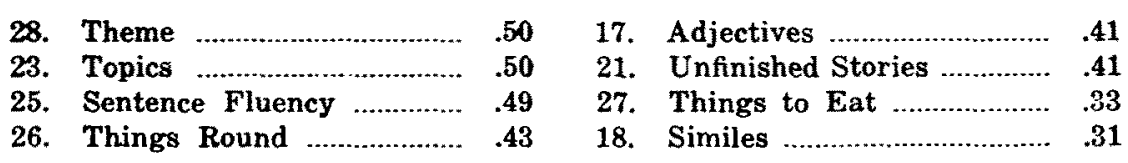

Factor $F$ is interpreted as ideational fluency ability, a facility in expressing ideas by the use of words and their meanings, quantity and not quality being the important thing. The quality of the material produced need only come within the limits of the meaning requirements of the test as interpreted by the subject. In the tests, words are produced through an associational process based on their meanings. The words are used as a means to an end, as tools in the expression of ideas. It should be noted that a person could obtain a good score in most of these tests by using relatively simple and common words.

The ideational fluency ability is measured in some cases by the number of words and in other cases by the number of phrases or sentences produced. It includes the production of meaningful phrases and sentences and also the listing of words where some meaning is required. The words written stand in some meaningful relation to other words written or implied.

Factor $F$ in some respects is similar to, but also is rather different from, Carroll's factor $E(1)$, which was interpreted as the rate of production of meaningful and syntactically coherent discourse where there is little restriction to definite responses. For example, Anagrams had a loading of .31 on Carroll's factor $E$, but failed to have an appreciable projection on his word fluency factor $A$. In the present study, however, Anagrams had a zero loading on factor $F$, but had a projection of $\mathbf{. 3 6}$ on the word fluency factor. Other tests with appreciable projections on Carroll's factor $E$ were Theme (number of words), Grammar, Similes, Picture Description (per cent relevant words), and Distorted English.

The directions on all tests on the present factor stressed quantity and not quality or coherence. Carroll's Theme test was scored in three different ways and his Picture Description test was scored in four ways, some sccres being essentially measures of quantity while others measured the quality of the responses. Consequently, the directions on these two tests could not have stressed only the quantity of the responses. The fact that a second score on the Picture Description test, the number of relevant words, did not have a high loading on 
Carroll's factor $E$, is pertinent at this point. Carroll states that this Picture Description score did not have an appreciable projection on factor $\mathrm{E}$ "because, it is believed, it is not directly a measure of coherence, but only a measure of the amount which the subject had to say." The present factor, however, is interpreted as measuring essentially the amount that the subject could express about a topic. In Topics and Theme, two of the best tests of this factor, the subjects were told explicitly to use all the ideas that they could think of, whether they seemed trivial or not.

Factor K.-The tests below had projections above .30 on this factor.

18. Similes

.51

20. Letter Star

.51

25. Sentence Fluency

21. Unfinished Stories

.33

13. Synonyms .......................... .32

It is possible that some of the variance on these tests can be attributed to individual differences in the ability to produce rapidly more than one answer that will satisfy the fairly restrictive requirements of each test. The factor may be tentatively interpreted as verbal versatility, the ability to express essentially the same idea by means of several different words or combinations of words. Thus, in the Similes, Sentence Fluency, and Synonyms tests, a person who is good in this ability can readily break the set of the first answer and produce a second answer, and then a third answer, that expresses the same general meaning. Others may find it difficult to break away from the first answer to restate the same idea in a somewhat different form. A task of rewriting certain phrases, sentences, or even paragraphs, woula be relatively easy for a person excelling in this ability.

It is likely that a related process occurs in the Letter Star test. Inasmuch as the series of words must be meaningful sentences or phrases and must also fit certain first-letter and number-of-word requirements, it is probable that subjects solve this test in the following manner: first, they produce a meaningful series of words according to some initial association, and then they alter the words used or the idea expressed until they arrive at an appropriate series of words. This type of revision might take place on each item where the first attempt is not completely appropriate, or it may even occur in the course of producing words in the first attempt.

The only explanation that could be found for the appearance of Unfinished Stories on this factor was that some revision process may be needed in this test to insure that the various details given in the beginning are properly included in the different stages of the story 
and also to insure that the story would not be concluded before time was called.

Factors $C$ and $E$ were not strongly determined and did not lend themselves readily to psychological interpretation, so no interpretation is given.

\section{Discussion}

The hypothesis that fluency is complex and that at least two factors would appear in the experimental portion of a battery including word fluency tests used by Thurstone and fluency tests used by British investigators was sustained. It is evident from the results that the tests of fluency used in British studies measure at least two quite separate fluency abilities, $W$ and $F$, the correlation between which was -.03. Tests of these two types have nearly always been combined in the same fluency battery assembled by different British investigators. For example, Cattell (5) had a fluency battery which included tests the same as or similar to First Letters, Topics, Things Round, Things to Eat, and Theme; and Studman (15) used a battery containing tests similar to Adjectives and Number of Letters plus a TwoSyllable test which would probably measure word fluency.

The two fluency factors obtained in the present study have been interpreted strictly in terms of cognitive processes. Inasmuch as the ideational fluency factor involves the amount that a person can express about a given topic and measures indirectly the flow of ideas, it is probably of more fundamental importance to language behavior than the word fluency factor, which involves the handling of words solely in terms of their structure.

Another possible distinction between the two fluency factors may be made in terms of a reported "tendency to be critical-minded." Stephenson described this critical-mindedness as the way in which one individual demands perfection whereas another is satisfied with less. In word fluency tests it is believed that any effects of criticalmindedness are minimized, for the subject has little or no freedom to form an individual conception of what responses would be appropriate. On the other hand, in the ideational fluency tests the subject has a great deal of freedom to establish his own conception of what answers are suitable. Thus, in the latter tests there is a possibility for the presumed critical-mindedness in an individual to operate with considerable effect.

There seems to be some similarity between the concept of surging mental activity operating against the screening barrier of criticalmindedness (or "inhibitions at lower levels") and the concept of 
Johnson and Reynolds $(\mathbf{1 0})$ * of two fundamental processes involved in verbal problem-solving, namely, the flow of various acts or responses and the selection of those responses which meet the requirements of the problem. Johnson and Reynolds state that possibly their flow factor is the same as the word fluency factor and their selection factor may be the usual verbal factor $V$. They also suggest that the two processes of flow and selection of responses might also be found in non-verbal problem-solving tasks. One might argue that a flow of responses is needed in some tests found in the present, quite separate factors $R, V$, and particularly in $W, F$, and $K$; and that a selection of responses, either a recognition selection or a screening selection, is functioning in tests found in every interpreted factor of the present study. Consequently, it is believed that although flow and selection of responses may be important aspects in the solution of some mental tasks, neither of them function at a highly significant level throughout a wide range of either verbal or non-verbal tests. In other words, it is believed that the flow of response in word fluency tasks and the flow of response in ideational fluency are not the same basic process. Likewise, the flow and selection of responses in reasoning $(R)$ tests are likely different processes from the flow and selection of responses functioning in other tests, such as tests found in factors $F$ or $K$.

Studman (15) and Stephenson (14) have reported that a battery of fluency tests has given indications of identifying some psychiatric types, especially manics. However, their batteries contained tests of each type of fluency found in the present study. The question thus arises as to the relation between each of these fluency abilities and different types of psychiatric cases.

There is some indication that ideational fluency cuts across both oral and written channels of expression. For example, according to Studman's findings, manics in their ideational flight are not only very fluent in speech but also can express themselves quite readily in written tests. Further study is needed on ideational fluency and also on word fluency to see if either of these factors transcends expression in writing and is present in oral expression. The verbal versatility factor needs to be studied to see if it will be substantiated further at the writing level. This factor should also be checked to see if it enters into oral expression.

More studies should be undertaken to compare the abilities involved in producing high quality written or spoken language with the fluency abilities that operate in quantity production. Studies

* The Paired Opposites test was taken from this study. 
should also be made of the abilities that function in the comprehension of spoken language.

It is believed that the main verbal abilities indicated to date are verbal comprehension $(V)$, word fluency $(W)$, ideational fluency $(F)$, verbal versatility, and Carroll's factor $H$, which is described as a facility in attaching appropriate names or symbols to stimuli.

Carroll's factor $H$ (1) seems to bear a close relation to the symptoms displayed by amnesic aphasics. This is an important indication, since the category of amnesic aphasia is one of the few usually found in most classifications of aphasia.

Factorial studies of verbal and non-verbal abilities can have an important bearing on future investigations of aphasia. Weisenberg and McBride say that in studying aphasics the results on tests are significant only so far as the examiner can determine what processes are involved in working the test. Since such tests have not yet been developed in sufficient variety to cover the whole field of mental functioning, they point out that temporarily, at least, every investigator has to employ tests not altogether satisfactory for the analysis of the processes involved (21, p. 89).

Factorial studies tend to identify more clearly the processes involved in mental tasks and thus give indications of important symptoms to look for in further studies of aphasia. On the other hand, results obtained in investigations of aphasia may provide substantiation for factorial results. For example, in speaking of the re-education of aphasic patients, Huber (9) mentions that some difficulty is encountered with patients showing recurrent utterances. Such utterances seem to be greatly influenced by the position of the speech mechanisms for the initial vowel or consonant in the words repeated. It is consequently possible to teach these patients to express a new word by selecting one with the same beginning sound as that in a recurrent word and by having the patient substitute this new word for the recurrent one. Then other words with the same and with different initial sounds can be substituted. After this, Huber further says that abstract words can be introduced in the form of propositions. This therapeutic technique seems to utilize initially a process similar to that of word fluency for breaking down the recurrent utterance, followed by a process of learning words in terms of propositional speech, which is essentially the way that words are used in the ideational fluency ability.

Another example particularly relevant to the present study is taken from a recent book on aphasia by Nielsen. Inasmuch as the clinical testing methods used in his investigation did not include exactly 
the same type of tasks as contained in the present fluency tests, the most direct evidence on fluency abilities that would be desirable on aphasics is not yet available. Nevertheless, some support for the separation of fluency into the two factors, word fluency and ideational fluency, can be obtained from Nielsen's statement that "significance is still not reminiscence; it is a higher function because one can recall a word of which the significance is unknown" $(12$, p. 73).

TABLE 1

The Battery of Tests*

\begin{tabular}{|c|c|c|c|c|c|c|}
\hline $\begin{array}{l}\text { Test } \\
\text { No. }\end{array}$ & $\begin{array}{l}\text { Test } \\
\text { Name }\end{array}$ & $\begin{array}{l}\text { Refer- } \\
\text { ence } \\
\text { Factor }\end{array}$ & \multicolumn{2}{|c|}{$\begin{array}{l}\text { Time } \\
\text { Limit } \\
\text { (min.) }\end{array}$} & $\begin{array}{l}\text { Scoring } \\
\text { Farmula }\end{array}$ & $\begin{array}{l}\text { Test- } \\
\text { ing } \\
\text { Order }\end{array}$ \\
\hline 1. & First Names & $\mathbf{M}$ & $3-2-7$ & 5 & No. right & 4 \\
\hline 2. & Word-Number & $\mathbf{M}$ & $3-2-6$ & 4 & No. right & 5 \\
\hline 3. & Identical Numbers & $\mathbf{P}$ & 2 & 4 & No. right & 1 \\
\hline 4. & Mirror Reading & $\mathbf{P}$ & 3 & 21 & No. right & 8 \\
\hline 5. & Letter Series & $\mathbf{R}$ & 5 & 41 & No. right & 6 \\
\hline 6. & Letter Grouping & $\mathrm{R}$ & 6 & $3 \mathbf{3}$ & No. right & 7 \\
\hline 7. & Addition & $\mathbf{N}$ & 3 & 6 & No. right & 10 \\
\hline 8. & Multiplication & $\mathbf{N}$ & 2 & 41 & No, right & 3 \\
\hline 9. & Same or Opposite & $\mathrm{V}$ & 2 & $4 \frac{1}{2}$ & No. right & 2 \\
\hline 10. & Completion & $\mathbf{V}$ & 2 & 43 & No. right & 9 \\
\hline 11. & First and Last Letters & . ...... & 3 & 4) & No. words & 14 \\
\hline 12. & Suffixes &..... & 2 & 4 & No. words & 12 \\
\hline 13. & Synonyms &..... & 3 & 31 & No. words & 28 \\
\hline 14. & 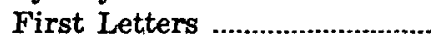 & $\ldots$ & 2 & $3 \frac{1}{2}$ & No. words & 11 \\
\hline 15. & Anagrams & . .... & 3 & 4 & No. words & 27 \\
\hline 16. & Disarranged Sentences ........... & . .... & 3 & 4 & No. right & 13 \\
\hline 17. & Adjectives & $\ldots$ & 2 & 4 & No. words & 15 \\
\hline 18. & Similes & . ..... & 2 & $5 k$ & No. phrases & 16 \\
\hline 19. & Paired Opposites & . .... & 1 & 4 & No. pairs & 17 \\
\hline 20. & Letter Star & . $\ldots . .$. & 2 & 9 & No. phrases & 18 \\
\hline 21. & 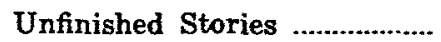 &.... & 1 & 7 & No. words & 19 \\
\hline 22. & Number of Letters & $\ldots$ & $\overline{2}$ & 3 & No. words & 20 \\
\hline 23. & Topics & $\ldots$ & 2 & 5 & No. phrases & 21 \\
\hline 24. & Given Letters & $\ldots$ & 2 & 31 & No. words & 22 \\
\hline 25. & Sentence Fluency & $\ldots$ & 3 & 7 & No. sent. & 23 \\
\hline 26. & Things Round & $\ldots$ & 2 & 23 & No. words & 24 \\
\hline 27. & Things to Eat & $\ldots$ & .. & 23 & Na words & 25 \\
\hline 28. & Theme & . .... & 1 & 6 & No. words & 26 \\
\hline
\end{tabular}

"Most of the subjects also completed a personality scale, "An Inventory of Factors STDCR," by J. P. Guilford. A later paper is planned in which the scores on these personality measures will be compared with composite scores on the main cognitive factors found in this study. 
TABLE 2

Product-Moment Correlations between the Tests*

\begin{tabular}{|c|c|c|c|c|c|c|c|c|c|c|c|c|c|c|}
\hline & 1 & 2 & 3 & 4 & 5 & 6 & 7 & 8 & 9 & 10 & 11 & 12 & 13 & 14 \\
\hline 1 & $\ldots$. & 35 & 02 & 15 & 22 & 28 & 02 & 11 & 21 & 18 & 09 & 23 & 14 & 12 \\
\hline 2 & 35 & .... & 04 & 14 & 20 & 24 & 20 & 22 & 16 & 10 & 17 & 18 & 13 & 26 \\
\hline 3 & 02 & 04 & $\ldots$ & 37 & $\mathbf{3 5}$ & 28 & 22 & 43 & 29 & 20 & 19 & 17 & 26 & 25 \\
\hline 4 & 15 & 14 & 37 & .... & 47 & 45 & 21 & 22 & 26 & 24 & 13 & 10 & 20 & 22 \\
\hline 5 & 22 & 20 & 35 & 47 & $\ldots$ & 53 & 23 & 27 & 47 & 41 & 20 & 29 & 33 & 33 \\
\hline 6 & 28 & 24 & 28 & 45 & 53 & $\ldots$. & 23 & 24 & 37 & 38 & 31 & 29 & 28 & 31 \\
\hline 7 & 02 & 20 & 22 & 21 & 23 & 23 & $\ldots$ & 62 & 09 & 07 & 22 & 22 & 02 & 18 \\
\hline 8 & 11 & 22 & 43 & 22 & 27 & 24 & 62 & ... & 25 & 13 & 20 & 17 & 6 & 24 \\
\hline 9 & 21 & 16 & 29 & 26 & 47 & 37 & 09 & 25 & $\ldots$ & 76 & 22 & 32 & 43 & 41 \\
\hline 10 & 18 & 10 & 20 & 24 & 41 & 38 & 07 & 13 & 76 & $\ldots$ & 26 & 35 & 40 & 37 \\
\hline 11 & 09 & 17 & 19 & 13 & 20 & 31 & 22 & 20 & 22 & 26 & $\ldots$ & 49 & 30 & 43 \\
\hline 12 & 23 & 18 & 17 & 10 & 29 & 29 & 22 & 17 & 32 & 35 & 49 & $\ldots$ & 35 & 55 \\
\hline 13 & 14 & 13 & 26 & 20 & 33 & 28 & 02 & 16 & 43 & 40 & 30 & $\mathbf{3 5}$ & $\ldots$ & 47 \\
\hline 14 & 12 & 26 & 25 & 22 & 33 & 31 & 18 & 24 & 41 & 37 & 43 & 55 & 47 & $\ldots$ \\
\hline 15 & 20 & 26 & 33 & 34 & 35 & 40 & 18 & 28 & 31 & 2 & 35 & 35 & 40 & 52 \\
\hline 16 & 21 & 10 & 31 & 22 & 36 & 37 & 07 & 23 & 72 & 63 & 19 & 32 & 45 & 40 \\
\hline 17 & 10 & 13 & 18 & 03 & 13 & 11 & -02 & 03 & 22 & 19 & 21 & 30 & 30 & 26 \\
\hline 18 & 06 & 08 & 27 & 18 & 32 & 37 & 12 & 17 & 38 & 38 & 15 & 24 & 41 & 31 \\
\hline 19 & 13 & 24 & 14 & 21 & 38 & 38 & 00 & 06 & 52 & 52 & 21 & 30 & 53 & 45 \\
\hline 20 & 03 & 09 & 22 & 18 & 21 & 30 & 16 & 22 & 26 & 21 & 26 & 26 & 40 & 40 \\
\hline 21 & 00 & -07 & 18 & 16 & 22 & 25 & 19 & 29 & 18 & 13 & -03 & 06 & 30 & 24 \\
\hline 22 & 17 & 22 & 23 & 34 & 46 & 43 & 18 & 22 & 38 & 38 & 45 & 41 & 39 & 66 \\
\hline 23 & 20 & 18 & 27 & 19 & 30 & 31 & 16 & 23 & 31 & 27 & 22 & 35 & 41 & 33 \\
\hline 24 & 22 & 21 & 22 & 18 & 31 & 34 & 14 & 23 & 44 & 43 & 47 & 51 & 42 & 54 \\
\hline 25 & $\overline{03}$ & 09 & 25 & 13 & 16 & 21 & 20 & 19 & 14 & 15 & 18 & 27 & 34 & 27 \\
\hline 26 & 06 & 19 & 27 & 14 & 22 & 30 & 10 & 15 & 17 & 13 & 18 & 16 & 24 & 20 \\
\hline 27 & 03 & 07 & 22 & 20 & 17 & 15 & 10 & 21 & 26 & 20 & 25 & 26 & 38 & 33 \\
\hline 28 & 18 & 01 & 17 & 07 & 22 & 23 & 13 & 15 & 31 & 25 & 16 & 31 & 26 & 27 \\
\hline
\end{tabular}

- The decimal point has been omitted for all entries, 
Table 2-Continued

\begin{tabular}{|c|c|c|c|c|c|c|c|c|c|c|c|c|c|c|}
\hline & 15 & 16 & 17 & 18 & 19 & 20 & 21 & 22 & 23 & 24 & 25 & 26 & 27 & 28 \\
\hline 1 & 20 & 21 & 10 & 06 & 13 & 08 & 00 & 17 & 20 & 22 & 03 & 06 & 08 & 18 \\
\hline 2 & 26 & 10 & 13 & 08 & 24 & 09 & -07 & 22 & 18 & 21 & 09 & 19 & 07 & 01 \\
\hline 3 & 33 & 31 & 18 & 27 & 14 & 22 & 18 & 23 & 27 & 22 & 25 & 27 & 22 & 17 \\
\hline 4 & 34 & 22 & 08 & 18 & 21 & 18 & 16 & 34 & 19 & 18 & 13 & 14 & 20 & 07 \\
\hline 5 & 35 & 36 & 13 & 32 & 38 & 21 & 22 & 46 & 30 & 31 & 16 & 22 & 17 & 22 \\
\hline 6 & 40 & 37 & 11 & 37 & 38 & 30 & 25 & 43 & 31 & 34 & 1 & 30 & 5 & 23 \\
\hline 7 & 18 & 07 & -02 & 12 & 00 & 16 & 19 & 18 & 16 & 4 & 20 & 10 & 0 & 13 \\
\hline 8 & 28 & 23 & 03 & 17 & 06 & 22 & 29 & 22 & 23 & 23 & 19 & 15 & 1 & 15 \\
\hline 9 & 31 & 72 & 22 & 38 & 52 & 26 & 18 & 38 & 31 & 44 & 14 & 17 & 26 & 31 \\
\hline 10 & 24 & 63 & 19 & 38 & 52 & 21 & 13 & 38 & 27 & 43 & 15 & 13 & 20 & 25 \\
\hline 11 & 35 & 19 & 21 & 15 & 21 & 26 & -03 & 45 & 22 & 47 & 18 & 18 & 25 & 16 \\
\hline 12 & 35 & 32 & 30 & 24 & 30 & 26 & 06 & 41 & 35 & 51 & 27 & 16 & 26 & 31 \\
\hline 13 & 40 & 45 & 30 & 41 & 53 & 40 & 30 & 39 & 41 & 42 & 34 & 24 & 38 & 26 \\
\hline 14 & 52 & 40 & 26 & 31 & 45 & 40 & 24 & 66 & 33 & 54 & 27 & 20 & 33 & 27 \\
\hline 15 & $\ldots$ & 37 & 20 & 17 & 34 & 28 & 20 & 54 & 27 & 48 & 26 & 20 & 37 & 20 \\
\hline 16 & 37 & $\ldots$ & 28 & 41 & 46 & 28 & 28 & 37 & 32 & 43 & 20 & 18 & 28 & 34 \\
\hline 17 & 20 & 28 & .... & 43 & 31 & 39 & 201 & 19 & 56 & 34 & 50 & 42 & 36 & 30 \\
\hline 18 & 17 & 41 & 43 & $\ldots$ & 44 & 60 & 47 & 30 & 60 & 32 & 63 & 41 & 35 & 29 \\
\hline 19 & 34 & 46 & 31 & 44 & $\ldots$ & 38 & 22 & 47 & 37 & 42 & 34 & 27 & 30 & 22 \\
\hline 20 & 28 & 28 & 39 & 60 & 38 & .... & 46 & 32 & 50 & 34 & 54 & 27 & 37 & 25 \\
\hline 21 & 20 & 28 & 20 & 47 & 22 & 46 & $\ldots .$. & 26 & 40 & 20 & 49 & 24 & 28 & 37 \\
\hline 22 & 54 & 37 & 19 & 30 & 47 & 32 & 26 & $\ldots$ & 25 & 46 & 26 & 19 & 25 & 23 \\
\hline 23 & 27 & 32 & 56 & 60 & 37 & 50 & 40 & 25 & $\ldots$ & 36 & 59 & 51 & 41 & 40 \\
\hline 24 & 48 & 43 & 34 & 32 & 42 & 34 & 20 & 46 & 36 & $\ldots$ & 31 & 33 & 34 & 28 \\
\hline 25 & 26 & 20 & 50 & 63 & 34 & 54 & 49 & 26 & 59 & 31 & $\ldots$. & 43 & 34 & 37 \\
\hline 26 & 20 & 18 & 42 & 41 & 27 & 27 & 24 & 19 & 51 & 33 & 43 & $\ldots$ & 29 & 28 \\
\hline 27 & 37 & 28 & 36 & 35 & 30 & 37 & 28 & 25 & 41 & 34 & 34 & 29 & $\ldots$ & 40 \\
\hline 28 & 20 & 34 & 30 & 29 & 22 & 25 & 37 & 23 & 40 & 28 & 37 & 28 & 40 & $\ldots$. \\
\hline
\end{tabular}


TABLE 3

The Centroid Factorial Matrix*

\begin{tabular}{|c|c|c|c|c|c|c|c|c|c|c|c|}
\hline $\begin{array}{l}\text { Test } \\
\text { No. }\end{array}$ & I & II & III & IV & $\mathbf{V}$ & VI & VII & VIII & $\mathbf{I X}$ & $\mathbf{X}$ & $h^{2}$ \\
\hline 1 & 28 & -18 & -10 & -07 & -03 & 41 & 11 & 13 & -31 & 18 & .452 \\
\hline 2 & 30 & -28 & $\mathbf{0 1}$ & 12 & -06 & 23 & 44 & 05 & -14 & -03 & .456 \\
\hline 3 & 45 & -14 & 15 & -17 & 02 & -12 & -06 & -33 & 12 & 12 & .430 \\
\hline 4 & 42 & -29 & 00 & -23 & -27 & -01 & -17 & -22 & 07 & -07 & .474 \\
\hline 5 & 58 & -25 & -13 & -29 & -22 & 10 & -0 & -07 & 08 & -05 & .577 \\
\hline 6 & 60 & -25 & -08 & -21 & -29 & 16 & -10 & 13 & 08 & -04 & .618 \\
\hline 7 & 33 & -39 & 43 & -18 & 19 & -14 & 08 & 20 & 10 & -11 & .602 \\
\hline 8 & 44 & -34 & 41 & -25 & 27 & -27 & 18 & 01 & -04 & 02 & .720 \\
\hline 9 & 65 & 11 & -43 & -34 & 20 & -05 & 19 & -06 & 06 & -09 & .829 \\
\hline 10 & 69 & 12 & -50 & -30 & 15 & 00 & 11 & $\infty$ & 19 & -07 & .786 \\
\hline 11 & 47 & -24 & -09 & 34 & 20 & 02 & -14 & 11 & 23 & 06 & .531 \\
\hline 12 & 56 & -14 & -14 & 23 & 29 & 11 & $-\infty$ & 19 & 10 & -14 & .576 \\
\hline 13 & 62 & 16 & -18 & 11 & -06 & -15 & 02 & -10 & -05 & 18 & .526 \\
\hline 14 & 67 & -16 & -17 & 31 & 05 & -18 & -01 & 06 & -08 & -04 & .646 \\
\hline 15 & 60 & -27 & -09 & 20 & -04 & -11 & -12 & -18 & -19 & -06 & .581 \\
\hline 16 & 64 & 16 & -34 & -29 & 19 & -11 & 09 & $\infty$ & -10 & -02 & .710 \\
\hline 17 & 48 & 36 & 15 & 25 & 07 & 23 & -01 & -14 & or & 03 & .528 \\
\hline 18 & 64 & 41 & 17 & -08 & -21 & -06 & 03 & 12 & 19 & 08 & .718 \\
\hline 19 & 61 & 18 & -29 & 10 & -22 & -05 & 24 & 00 & 03 & -12 & .622 \\
\hline 20 & 59 & 25 & 20 & 11 & $-\overline{-15}$ & -21 & -05 & 14 & 09 & 13 & .576 \\
\hline 21 & 45 & 26 & 27 & -17 & -18 & -23 & -18 & 17 & -25 & -05 & .584 \\
\hline 22 & 65 & -27 & -22 & 19 & -16 & -18 & -06 & 09 & -04 & -14 & .671 \\
\hline 23 & 66 & 30 & 29 & 04 & -04 & 25 & 02 & -03 & 01 & 08 & .683 \\
\hline 24 & 66 & -04 & -19 & 24 & 17 & 05 & -01 & 05 & 04 & -03 & .567 \\
\hline 25 & 57 & 34 & 41 & 15 & -14 & -01 & -06 & 13 & 08 & -01 & .678 \\
\hline 26 & 47 & 19 & 26 & 08 & -08 & 27 & 01 & -13 & 08 & -16 & .459 \\
\hline 27 & 51 & 19 & 11 & 14 & 10 & -05 & -15 & -16 & -14 & -06 & .412 \\
\hline 28 & 47 & 20 & 08 & -06 & 19 & 08 & -24 & 09 & -22 & -11 & .440 \\
\hline$\Sigma$ & 1496 & -01 & -01 & -03 & -06 & -02 & 00 & 25 & 06 & -52 & \\
\hline
\end{tabular}

- The doctmal point has been ounltted for all factor boadinger 
TABLE 4

The Rotated Factorial Matrix*

\begin{tabular}{|c|c|c|c|c|c|c|c|c|c|c|}
\hline $\begin{array}{l}\text { Test } \\
\text { No. }\end{array}$ & $\mathbf{M}$ & $\mathbf{P}$ & $\mathbf{R}$ & $\mathbf{N}$ & V & $\mathbf{w}$ & $\mathbf{F}$ & $\mathbf{K}$ & C & $\mathbf{E}$ \\
\hline 1 & 59 & 02 & 06 & 00 & -01 & 01 & 15 & -04 & 01 & -01 \\
\hline 2 & 34 & -05 & 00 & 30 & 03 & -05 & -04 & -01 & 35 & 05 \\
\hline 3 & -04 & 49 & 23 & 24 & 01 & -01 & -05 & 05 & 00 & -02 \\
\hline 4 & 01 & 28 & 55 & 03 & -02 & -04 & -05 & -05 & 00 & 06 \\
\hline 5 & 14 & 19 & 49 & 01 & 17 & -04 & 00 & -01 & 01 & 00 \\
\hline 6 & 22 & 01 & 47 & -08 & 09 & 03 & $\infty$ & 08 & -01 & 00 \\
\hline 7 & 00 & 00 & 05 & 59 & -07 & 02 & 09 & -01 & 02 & -03 \\
\hline 8 & 04 & 28 & -06 & 71 & 02 & -03 & 01 & 05 & 00 & 08 \\
\hline 9 & -02 & 20 & 01 & 06 & 74 & -04 & -04 & -02 & 06 & 04 \\
\hline 10 & -02 & 05 & 03 & -07 & 74 & 02 & -04 & 02 & -01 & -06 \\
\hline 11 & -03 & 06 & 00 & 00 & -01 & 56 & $\mathbf{0 0}$ & 00 & -07 & -08 \\
\hline 12 & -01 & -07 & -01 & 00 & 16 & 60 & 19 & -13 & 04 & 00 \\
\hline 13 & 06 & 27 & -04 & -05 & 24 & 20 & 01 & 32 & -01 & 22 \\
\hline 14 & -01 & 10 & -02 & 05 & 13 & 48 & 00 & 12 & $\mathbf{\infty}$ & 34 \\
\hline 15 & $\mathbf{0 3}$ & 28 & 21 & 04 & -04 & 36 & 01 & -04 & 02 & 38 \\
\hline 16 & $\mathbf{0 3}$ & 27 & -08 & 08 & 60 & 01 & 05 & 03 & -01 & 17 \\
\hline 17 & 02 & 10 & -04 & -0 & 02 & 15 & 41 & 12 & 30 & -06 \\
\hline 18 & 00 & 00 & 02 & $\mathbf{0 1}$ & 23 & -06 & 31 & 51 & 12 & $\mathbf{0 0}$ \\
\hline 19 & -01 & -02 & 0.5 & -06 & 43 & 03 & 01 & 25 & 27 & 28 \\
\hline 20 & -02 & 04 & -05 & 05 & 06 & 15 & 23 & 51 & $\mathbf{0 0}$ & 14 \\
\hline 21 & 03 & -02 & 04 & 03 & 01 & -02 & 41 & $\mathbf{3 3}$ & -09 & 37 \\
\hline 22 & -02 & 02 & 21 & -01 & 13 & 38 & -06 & 10 & $\mathbf{0 0}$ & 36 \\
\hline 23 & 19 & 10 & $\overrightarrow{05}$ & 06 & 02 & 01 & 50 & 24 & 27 & -05 \\
\hline 24 & 03 & 07 & -02 & -02 & 21 & 43 & 12 & 02 & 08 & 09 \\
\hline 25 & -02 & -07 & $\mathbf{0 0}$ & 07 & $-0 \pi$ & $\infty$ & 49 & 40 & 20 & $\boldsymbol{n}$ \\
\hline 26 & $\mathbf{0 0}$ & 01 & 20 & 08 & -08 & -02 & 43 & $\mathbf{0 1}$ & 41 & -0.5 \\
\hline 27 & -07 & 20 & 00 & 00 & 01 & 23 & 33 & 04 & 10 & 24 \\
\hline 28 & 05 & 01 & $\mathbf{0 0}$ & -07 & 08 & 21 & 50 & -05 & -02 & 17 \\
\hline $\bar{\Sigma}$ & 151 & 282 & 240 & 193 & 388 & 356 & 406 & 284 & 204 & 265 \\
\hline
\end{tabular}

- The decimal point has been onitted for all entrien. 
TABLE 5

The Final Transformation Matrix

\begin{tabular}{rrrrrrrrrrr}
\hline & $\mathrm{M}$ & $\mathrm{P}$ & $\mathrm{R}$ & $\mathrm{N}$ & $\mathrm{V}$ & $\mathrm{W}$ & $\mathrm{F}$ & $\mathrm{K}$ & $\mathrm{C}$ & $\mathrm{E}$ \\
\hline $\mathrm{I}$ & .12 & .22 & .15 & .13 & .25 & .24 & .26 & .20 & .12 & .17 \\
$\mathrm{II}$ & -.19 & -.16 & -.35 & -.36 & .33 & -.20 & .45 & .33 & .16 & .02 \\
$\mathrm{III}$ & .01 & .01 & -.01 & .54 & -.59 & -.20 & .45 & .15 & .23 & -.09 \\
$\mathrm{IV}$ & -.13 & -.17 & -.28 & -.18 & -.39 & .65 & .00 & .09 & .22 & .21 \\
$\mathrm{~V}$ & -.13 & .17 & -.54 & .30 & .23 & .34 & .13 & -.44 & -.11 & -.22 \\
VI & .52 & -.18 & .29 & -.27 & -.18 & -.10 & .44 & -.40 & .35 & -.53 \\
VII & .18 & -.11 & -.41 & .60 & .40 & -.51 & -.33 & .21 & .57 & -.02 \\
VIII & .25 & -.76 & -.31 & -.04 & .10 & .22 & .22 & .31 & -.30 & -.05 \\
IX & -.45 & -.05 & .18 & .02 & .18 & -.01 & -.27 & .10 & .09 & -.71 \\
$\mathrm{X}$ & .58 & .50 & -.32 & .00 & -.18 & .08 & -.30 & .56 & -.55 & -.30 \\
\hline
\end{tabular}

TABLE 6

Cosines of Angles between Reference Vectors

\begin{tabular}{|c|c|c|c|c|c|c|c|c|c|c|}
\hline & $\mathbf{M}$ & $\mathbf{P}$ & $\mathbf{R}$ & $\mathrm{N}$ & $\mathrm{V}$ & $\mathrm{W}$ & $\mathrm{F}$ & $\mathbf{K}$ & C & $\mathbf{E}$ \\
\hline $\mathbf{M}$ & 1.00 & ....... & ....... & $\ldots . . .$. & $\ldots . .$. & $\ldots . .$. & $\ldots$ & $\ldots \ldots$ & $\ldots$ & $\ldots$ \\
\hline $\mathbf{P}$ & .07 & 1.00 & ....... & $\ldots$ & $\ldots \ldots$ & ....... & $\ldots$ & $\ldots \ldots$ & $\ldots \ldots$ & $\ldots . .$. \\
\hline $\mathbf{R}$ & -.08 & .10 & 1.00 & $\ldots$ & ...... & ....... & $\ldots$ & $\ldots$ & $\ldots . .$. & ....... \\
\hline $\mathbf{N}$ & .02 & .19 & -.28 & 1.00 & $\ldots . .$. & ....... & $\ldots \ldots$ & $\ldots . .$. & $\ldots \ldots$ & $\ldots$ \\
\hline V & -.20 & -.08 & -.24 & .02 & 1.00 & ........ & ......... & ........ & ........ & $\ldots . . .$. \\
\hline $\mathbf{w}$ & -.10 & -.02 & -.17 & -.31 & -.24 & 1.00 & 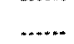 & $\ldots . . .$. & ....... & $\ldots . . .$. \\
\hline $\mathbf{F}$ & .11 & -.33 & .05 & -.18 & -.21 & .08 & 1.00 & ....... & $\ldots . .$. & $\ldots$ \\
\hline $\mathbf{K}$ & .20 & -.01 & -.33 & .06 & .04 & -.09 & -.16 & 1.00 & ....... & $\ldots$ \\
\hline C & -.18 & -.23 & .11 & .27 & .09 & -.38 & .23 & -.23 & 1.00 & $\ldots$ \\
\hline $\mathbf{E}$ & -.13 & -.02 & -.08 & -.02 & -.02 & .15 & .03 & .10 & -.01 & 1.00 \\
\hline
\end{tabular}

TABLE 7

Correlations between the Primary Vectors

\begin{tabular}{|c|c|c|c|c|c|c|c|c|c|c|}
\hline & $\mathbf{M}$ & $\mathbf{P}$ & $\mathbf{R}$ & $\mathbf{N}$ & $\mathrm{V}$ & $\mathbf{W}$ & $\mathbf{F}$ & $\mathbf{K}$ & C & $\mathbf{E}$ \\
\hline $\mathbf{M}$ & 1.00 & $\ldots \ldots$ & ....... & $\ldots . . .$. & ....... & $\ldots$ & $\ldots \ldots$ & ........ & $\ldots$ & $\ldots$ \\
\hline $\mathbf{P}$ & .06 & 1.00 & ....... & $\ldots \ldots$ & $\ldots . .$. & ....... & $\ldots$ & $\ldots .$. & ....... & $\ldots$ \\
\hline $\mathbf{R}$ & .12 & -.16 & 1.00 & $\ldots . .$. & $\ldots \ldots$ & $\ldots$ & $\ldots$ & $\ldots .$. & $\ldots . . .$. & $\ldots . . .$. \\
\hline $\mathbf{N}$ & .02 & -.24 & .44 & 1.00 & $\ldots \ldots$ & ........ & $\ldots . . .$. & ....... & ...... & $\ldots . .$. \\
\hline$V$ & .23 & .06 & .37 & .23 & 1.00 & ........ & ........ & ....... & ......... & $\ldots$ \\
\hline $\mathbf{W}$ & .22 & .01 & .38 & .31 & .35 & 1.00 & $\ldots \ldots$ & ....... & ....... & $\ldots$ \\
\hline$F$ & -.18 & .26 & .08 & .19 & .22 & -.03 & 1.00 & ....... & ............ & ....... \\
\hline $\mathbf{K}$ & -.13 &, 10 & .32 & .06 & .10 & .24 & .14 & 1.00 & ....... & $\ldots$ \\
\hline $\bar{C}$ & .20 & .24 & -.08 & -.29 & -.03 & .32 & .25 & .20 & 1.00 & $\ldots$ \\
\hline $\mathbf{E}$ & .14 & -.02 & .02 & -.01 & .01 & -.13 & .04 & -.14 & -.04 & 1.00 \\
\hline
\end{tabular}


TABLE 8

The Factorial Pattern*

\begin{tabular}{|c|c|c|c|c|c|c|c|c|c|c|c|}
\hline $\begin{array}{l}\text { Test } \\
\text { No. }\end{array}$ & $\begin{array}{l}\text { Test } \\
\text { Name }\end{array}$ & $\mathbf{M}$ & $\mathbf{P}$ & $\mathbf{R}$ & $\mathbf{N}$ & V & $\mathbf{W}$ & $\mathbf{F}$ & $\mathbf{K}$ & C & $\mathbf{E}$ \\
\hline 1. & & & -. & $\ldots$. & .... & ... & … & ... & $\ldots$ & .... & \\
\hline 2. & & & $\ldots$. & .... & 30 & $\ldots$. & $\ldots$. & $\ldots$ & $\ldots$ & 35 & $\ldots$. \\
\hline 3. & 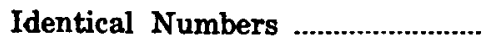 & $\ldots$. & 49 & $\ldots$. & $\ldots$. & $\ldots$. & $\ldots .$. & .... & ... & .... & $\cdots$ \\
\hline 4. & 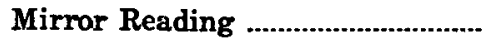 & $\ldots$. & $\ldots$. & 55 & ... & $\ldots$. & $\ldots$. & $\cdots$ & & $\cdots \cdot$ & \\
\hline 5. & ...................... & $\ldots$. & .... & 49 & $\ldots$ & .... & $\ldots$ & $\ldots$. & ... & $\ldots$. & \\
\hline 6. & g & .... & .... & 47 & .... & .... & $\ldots$ & .... & $\ldots$ & .... & $\cdots$. \\
\hline 8. & 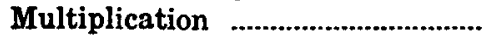 & .... & $\ldots$ & $\ldots$. & 71 & $\ldots$ & $\ldots$. & $\ldots$. & $\cdots$ & .... & $\cdots$ \\
\hline 7. & Ad & & .. & ... & 59 & 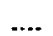 & .... & .... & $\ldots$ & .... & $\cdots .$. \\
\hline 9. & & & & & $\ldots .$. & 74 & .... & .... & 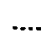 & ... & $\cdots$ \\
\hline 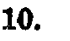 & & & & & & 74 &. & . & & ... & $\cdots$ \\
\hline & $\mathrm{Di}$ & & & & & 60 & & $\cdots$ & & ... & $\cdots$ \\
\hline & & & & & & 43 & $\cdots$ & $\ldots$. & & $\cdots$ & \\
\hline & Fi & & & & & $\ldots$. & 56 & & & ... & \\
\hline & Su. & & & & & $\cdots$ & 50 & & & & \\
\hline & $\mathbf{F i}$ & & & & & $\cdots$ & 48 & & & & 34 \\
\hline & & & & & & $\ldots$. & 43 & & & $\ldots$ & \\
\hline & No & & & & & $\cdots$ & 38 & & & $\cdots$ & 36 \\
\hline & An & & & & & $\cdots \cdot$ & 36 & • & ..... & ... & 38 \\
\hline & $\mathrm{Th}$ & & & 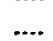 & & & $\ldots$. & 5 & & $\ldots$ & \\
\hline & To & & & & & & & 50 & & & \\
\hline 5. & Se & & & & & & & 49 & 40 & & \\
\hline & Th & & & & & & & 43 & 然 & 41 & \\
\hline 1 & Un & & & & & & & 41 & 33 & $\ldots$ & 37 \\
\hline 7 & Ad & & & & & . & & 41 & - & 30 & \\
\hline 27 & Th & & & . & & $\ldots$. & & 33 & & $\ldots$. & \\
\hline 18 & Sir & & .. & $\ldots$ & .. & $\because>>>$ & $\ldots$. & 31 & & $\cdots$ & \\
\hline & & & .. & ... & .. & $\ldots$ & $\ldots$ & $\ldots .$. & & & \\
\hline 3. & Synonym & & $\cdots$ & $\ldots$. & $\ldots$ & $\ldots$. & .... & $\ldots$. & 32 & $\ldots$ & \\
\hline
\end{tabular}

* The decimal point has been omitted for all entries. Only loadings of 30 or higher are entered in the table. 


\section{REFERENCES}

1. Carroll, John B. A factor analysis of verbal abilities. Psychometrika, 1941, 6, 279-307.

2. Carroll, John B. The factorial representation of mental ability and academic achievement. Educ. psychol. Meas., 1943, 3, 307-332.

3. Cattell, Raymond B. Temperament tests. I. Temperament. Brit. J. Psychol, 1932-33, 23, 308-329.

4. Cattell, Raymond B. Temperament tests. II. Tests. Brit. J. Psychol., 1933$34,24,20-49$.

5. Cattell, Raymond B. A guide to mental testing. London: Univ. London Press, 1936.

6. Coombs, Clyde H. A criterion for significant common factor variance. Psychometrika, 1941, 6, 267-272.

7. Goldstein, K. The problem of the meaning of words based upon observation of aphasic patients. J. Psychol., 1935, 2, 301-316.

8. Hargreaves, H. L. The "faculty" of imagination. Brit. J. Psychol., Monograph Supplements, No. 10. Cambridge: Cambridge Univ. Press, 1927.

9. Huber, Mary. Re-education of aphasics. J. speech Disorders, 1942, 7, 289-293.

10. Johnson, D. M. and Reynolds, F. A factor analysis of verbal ability. Psychol. Record, 1941, 4, 183-195.

11. Lashley, Karl S. Coalescence of neurology and psychology. Proc. Amer. philos. Soc., 1941, 84, 461-470.

12. Nielson, J. M. Agnosia, apraxia, aphasia: their value in cerebral localization. 2d ed. revised. New York: Paul B. Hoeber, Inc., Medical Books, Harper Bros., 1946.

13. Notcutt, B. Perseveration and fluency. Brit. J. Psychol., 1943, 33, 200-208.

14. Stephenson, W. and others. Spearman factors and psychiatry. Brit. J. med. Psychol., 1934, 14, 101-135.

15. Studman, L. Grace. Studies in experimental psychiatry. V. ' $w$ ' and 'f' factors in relation to traits of personality. J. ment. Science, 1935, 81, 107-137.

16. Thurstone, L. L. Multiple-factor analysis. Chicago: Univ. Chicago Press, 1947.

17. Thurstone, L. L. Primary mental abilities. Psychometric Monographs, No. 1. Chicago: Univ. Chicago Press, 1938.

18. Thurstone, L. L. An experimental study of simple structure. Psychometrika, 1940, 5, 153-168.

19. Thurstone, L. L. A single plane method of rotation. Psychometrika, 1946, 11, 71-79.

20. Thurstone, L. L. and Thurstone, T. G. Factorial studies of intelligence. Psychometric Monographs, No. 2. Chicago: Univ. Chicago Press, 1941.

21. Weisenberg, Theodore and McBride, Katherine E. Aphasia, a clinical and psychological study. New York: The Commonwealth Fund, 1935. 